\title{
Critical Buckling Time of Compressed Steel Bars Considering High Temperature Creep
}

\author{
Agata Włóka, Kamil Pawłowski, Wrocław University of Environmental and Life Sciences
}

\begin{abstract}
Steel structures are sensitive to the risks associated with elevated temperatures, especially in the range of fire temperatures. This applies in particular to slender compressed elements such as columns, truss rods etc. These hazards are not only related to the deterioration of the mechanical properties of steel at elevated temperatures, increased deformations and stresses, but they may also cause short-term high temperature creep, which can lead to rapid loss of stability of compressed elements in a short time, with stresses significantly lower than Euler's critical stresses. Thus, for safety reasons it is important to know the time for which the structure will retain its load capacity. This paper presents the results of calculation of the critical time, after which the total loss of stability of the axially compressed prismatic steel bar occurs. Calculations were made with the use of the initial imperfection method, taking into account experimentally determined relationship between creep strain and time, in the form of $\varepsilon_{c}=f(\sigma, t)=k \sigma^{n} t$. The results of theoretical calculations were compared with the creep times obtained in the experimental creep tests of axially compressed steel members at elevated temperatures. Laboratory short-term creep tests were performed in the Instron/Satec KN 600 universal testing machine equipped with a furnace for high-temperature testing type SF-16 2230, that enables testing at temperatures up to $1200^{\circ} \mathrm{C}$. This paper presents only a part of the research and analyses conducted for ordinary structural steel, at $700^{\circ} \mathrm{C}$.

Keywords: fire temperatures, structural steel, structural stability, short-time creep
\end{abstract}

\section{Introduction}

The load capacity of steel structures at elevated temperatures, especially at the fire temperature ranges, depends on many factors. These include a significant decrease in the strength of steel, accompanied by a rise in temperature, lowered elasticity modulus and the associated decrease in stiffness of the elements, or the increase in stress resulting from the thermal expansion of the elements. Another factor that must be taken into account when bearing capacity of steel structures is determined at elevated temperatures is creep, which is significantly accelerated by high temperature. This applies in particular to slender construction elements that work under compressive loads, such as columns or compressed bars of trusses. Accelerated creep may cause such elements to rapidly lose stability at loads much lower than would be expected from the theoretical value of Euler's critical load. This problem is ignored both in the European standards EUROCODE 3 and US AISC, which can lead to significant errors in the design of compressed steel elements subjected to fire [4].

Creep may be defined briefly as an increase in deformation of the element as a function of time under constant load. The creep phenomenon occurs at any temperature and even at small values of loads. However, at temperatures of fire, creep becomes particularly important, and it may determine the load capacity of the designed structural elements [2].

The dependence of the strain increase over time is usually presented in the form of the so-called creep curve $[2,3,5]$. The idealised creep curve is shown in Figure 1.

There are three characteristic ranges on this curve. The first range - primary creep - begins at the time of occurrence of the initial strain associated with the load applied to the element. This stage is characterized by the decrease in creep rate as a function of time. Creep rate decreases until the minimum value is reached. Upon reaching the minimum creep rate the second range begins - the socalled secondary creep or steady-state creep. The value of creep rate in this stage is constant. The third range - tertiary creep - is characterised by an increasing creep rate, leading to the failure of the element in a relatively short time.

Practical applications often use the power relationship between the minimum creep rate during the second stage and stress in a cross section of the element [1].

$$
\dot{\varepsilon}_{c, \min }=f(\sigma)=k \sigma^{n}
$$

Parameters $k$ and $n$ of the above equation should be determined by experimental investigations. 


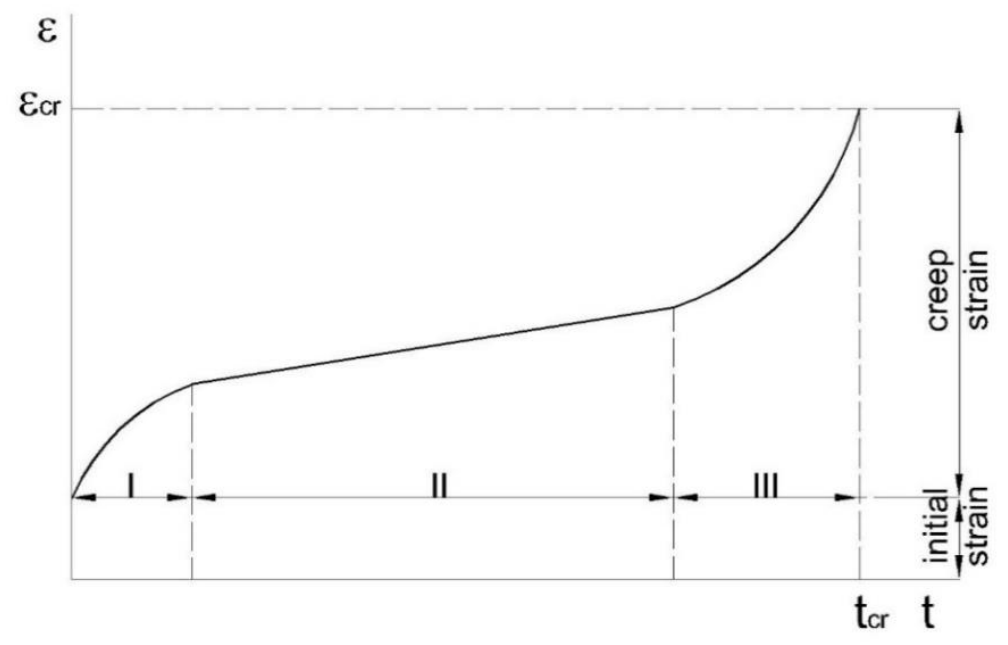

Fig. 1. Idealised creep curve

In this paper the authors attempted to theoretically predict the critical time of the loss of stability of the axially compressed steel element due to creep. Time prediction of the loss of stability was based on the method of initial imperfections. For the application of this method, it was necessary to determine the parameters of the power creep law for the investigated steel. Parameters of the creep law were determined based on the laboratory tensile creep tests at an elevated temperature. The results of the predictions were compared with the experimental data, collected during laboratory buckling creep tests.

\section{Materials and methods}

The tests were conducted on samples of ordinary structural S235JR steel. The chemical composition of the steel is provided in Table 1. The chemical composition was determined using a BAIRD-DV4 optical emission spectrometer. The tests and analyses presented in this paper were conducted at a temperature of $700^{\circ} \mathrm{C}$.

TABLE 1

Chemical composition of the S235JR steel

\begin{tabular}{|l|l|}
\hline Element & Content [\%] \\
\hline $\mathrm{C}$ & 0.13 \\
\hline $\mathrm{Mn}$ & 0.58 \\
\hline $\mathrm{Si}$ & 0.19 \\
\hline $\mathrm{P}$ & 0.02 \\
\hline $\mathrm{S}$ & 0.03 \\
\hline $\mathrm{Cr}$ & 0.04 \\
\hline $\mathrm{Ni}$ & 0.10 \\
\hline $\mathrm{Mo}$ & 0.02 \\
\hline $\mathrm{V}$ & 0.00 \\
\hline $\mathrm{Cu}$ & 0.21 \\
\hline $\mathrm{Ti}$ & 0.00 \\
\hline
\end{tabular}

The laboratory tests consisted of two series of tests.

The first series included steel creep tests at elevated temperatures. During these tests, samples were subjected to constant tensile stresses of different values. The aim of the study was to determine the relationship between the creep rate determined in the second stage of creep and the stresses in the cross section of the sample. The analyses were carried out on samples of a round cross section with a diameter of $10 \mathrm{~mm}$, made in accordance with the recommendations of PN-EN ISO 6892-1: 2010 [6]. The data collected during the tensile creep tests were used to determine the parameters of the power creep law, which was necessary to calculate the critical buckling times, using initial imperfections method.

The second series of tests was a study of the effect of creep at elevated temperatures on the buckling of steel elements subjected to compressive loads of different values. Test specimens were made in the form of prismatic bars with a rectangular crosssection of $12 \times 30 \mathrm{~mm}$ and a length of $500 \mathrm{~mm}$. Support types of the specimens during the tests were hinged on both ends.

Both series of tests were performed in the SATEC / Instron KN600 universal testing machine. An SF-16 2230 high temperature furnace was used to heat the samples. The temperature of the samples placed inside the furnace was controlled by a cRIO-9076 controller equipped with an NI 9211 thermocouple module and a K-type thermocouple. Horizontal displacements in the buckling tests were measured using a Soltron ACR 100 LVTD sensor. The measuring site is shown in Figure 2 

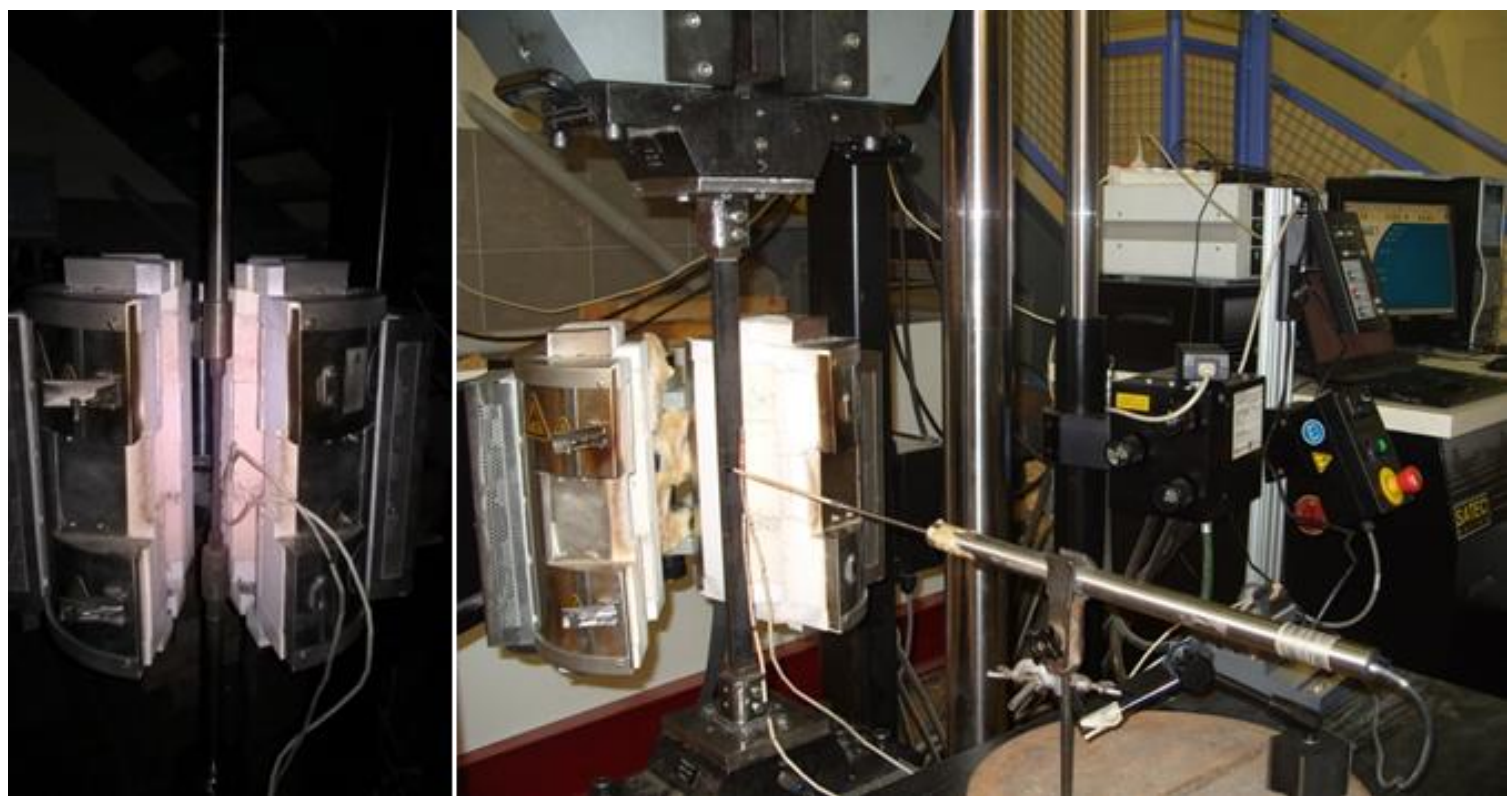

Fig. 2. Test site: left for testing tensile creep, right for buckling tests

\section{Results of the tensile creep tests}

As a result of the tests, the creep curves shown in Figure 3 were obtained. For each creep curve, the minimum creep rate in the second stage was determined. Then the relationship between the minimum creep rate and the tensile stress (Fig. 4) in

the form of the function $\dot{\varepsilon}_{c}=f(\sigma)=k \sigma^{n}$ was determined. For S235JR steel at a temperature of $700^{\circ} \mathrm{C}$ the $k$ value was $4.65 \cdot 10^{-13}\left[\mathrm{MPa}^{-\mathrm{n}} \cdot \mathrm{s}^{-1}\right]$, while $n$ was 4.83. A detailed discussion of the results is given in the paper [9].

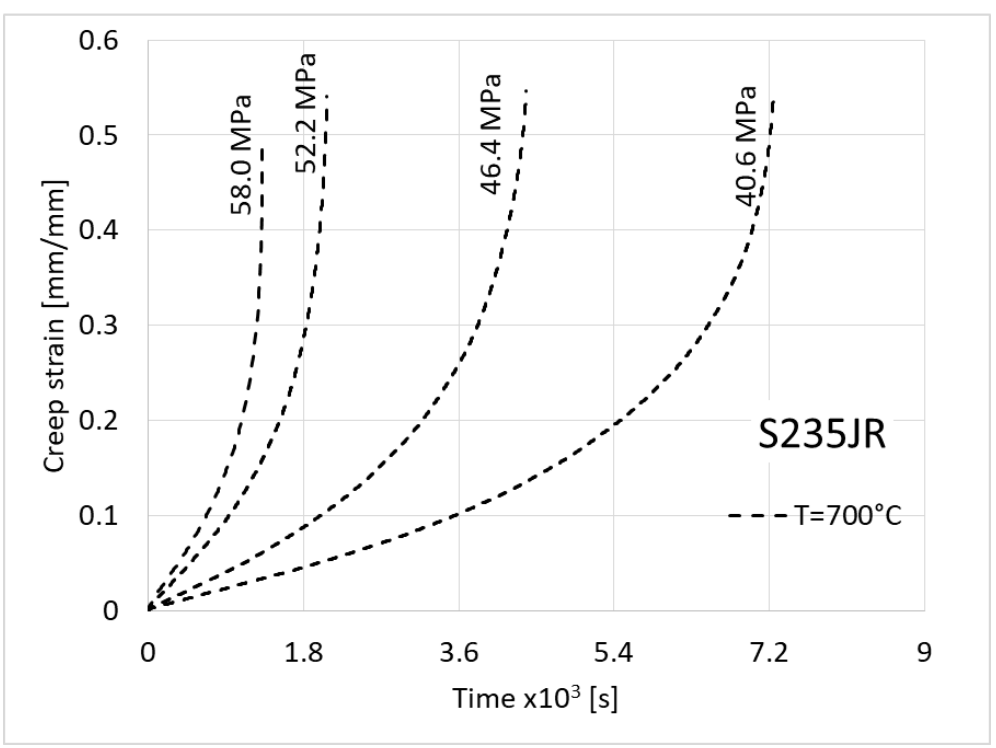

Fig. 3. Creep curves of S235JR steel at the temperature of $700^{\circ} \mathrm{C}$ 


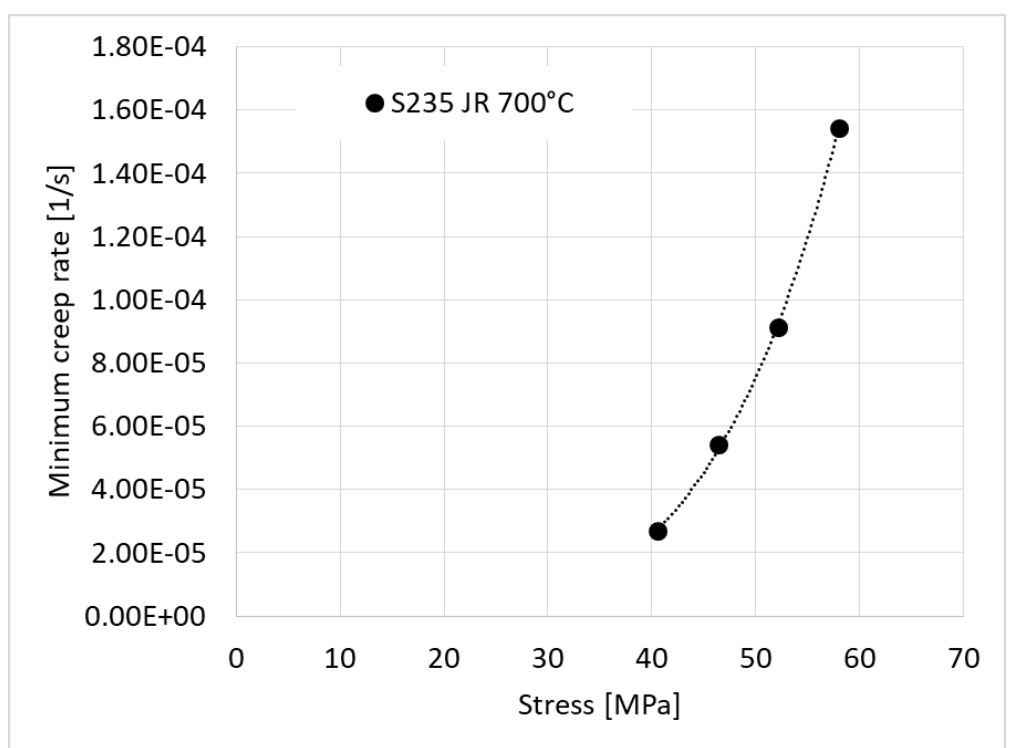

Fig. 4. Relationship between minimum creep rate and tensile stress for S235JR steel at $700{ }^{\circ} \mathrm{C}$

Results of the investigations on the impact of creep on the buckling of steel elements

As a result of the tests on the influence of creep on the buckling of axially compressed steel elements, the relationship between the buckling magnitude - the displacement perpendicular to the axis of the test piece in the middle of its length - and the time of load of the test specimens were determined. Sample relationships obtained during the tests are shown in Fig. 5. For S235JR steel at $700^{\circ} \mathrm{C}$, the time after which the total loss of stability of the tested elements occurred ranged from 2 to 3 hours, depending on the magnitude of the load applied to the sample. A wider discussion of the results of the research has been provided in the paper [8].

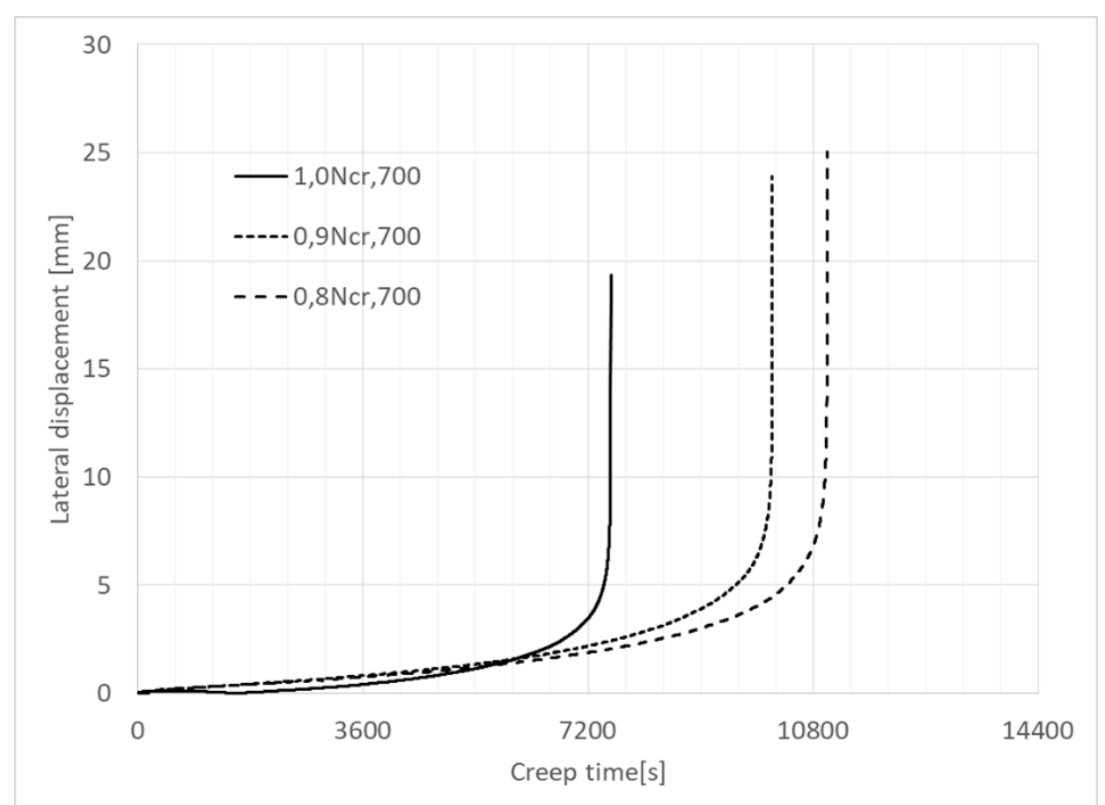

Fig. 5. Sample relationship between lateral buckling displacement and creep time, S235JR steel at the temperature of $700^{\circ} \mathrm{C}$ 


\section{Theoretical Findings}

In this paper the authors attempted to theoretically determine the time after which the loss of stability of the axially compressed steel bar operating at elevated temperature occurs. For this purpose, the initial imperfection method described in the work [7] was used. This method is based on the assumption that the rod before the load is pre-bent - has an initial imperfection of value $v_{0}$ (Fig. 6.)

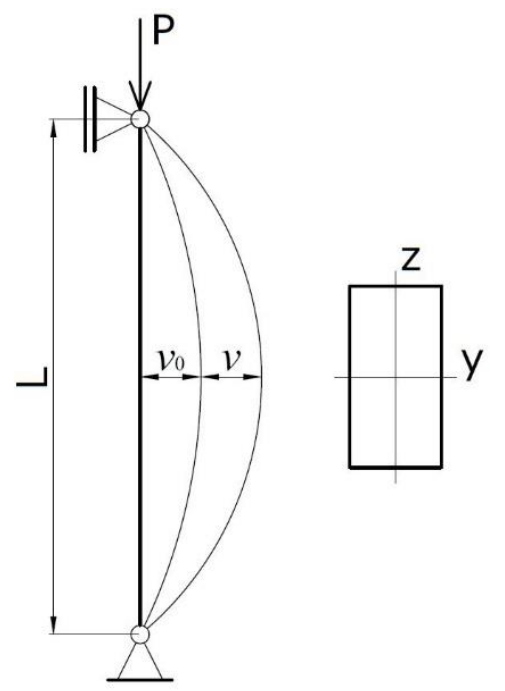

Fig. 6. Buckling of axially loaded compression member

The analyses presented in this paper assume the value of the initial imperfection:

$$
v_{0}=0.01 \sin \frac{\pi x}{l}
$$

When force $P$ is applied, the deflection of the element increases by the value $v$. Since the axis of the bent element does not coincide with the axis of action of force $P$, an additional bending moment of value

$$
M=P\left(v_{0}+v\right)
$$

is generated in the element, and the stresses in any of the cross-sectional levels are

$$
\sigma=\frac{P}{A}-\frac{M y}{J}
$$

The equation above demonstrates that the normal stresses in the different cross-sectional levels will vary, and consequently, that the plastic strains caused by creep will not be constant at the different crosssectional levels. In this study the value of plastic strains caused by creep is determined from the equation:

$$
\varepsilon_{c}=f(\sigma, t)=t k \sigma^{n}
$$

assuming, based on previous research, $k=4.65 \cdot 10^{-13}$ $\left[\mathrm{MPa}^{-\mathrm{n}} \cdot \mathrm{s}^{-1}\right]$ and $n=5$.
Knowing the increase in strains in the individual levels of the cross section, which will cause creep after time $t$ from the initial load, the curvature increment of the analyzed element can be determined, and thus also increase in the deflection $\Delta v$ caused by creep. By repeating the calculations for the increasing time $t$, the relationship between the increase of the deflection of the element and the time may be determined, as well as the critical time, after which the loss of stability of the bar occurs. The sample results of the calculation and the method of determining the predicted critical time are presented in Figure 7.

As can be seen in Figure 7, the relationship between the theoretically predicted lateral deflection of the element and the creep time is similar to that obtained in laboratory tests, which is shown in Figure 5. Also, the magnitude of the critical buckling time obtained is similar for both methods.

Figure 8 presents the theoretical calculations of the critical buckling times and their comparison with the times obtained in laboratory tests. In both cases, the time after which the complete loss of stability of the analyzed element occurs decreases with the increase of normal stress in the cross section due to force $P$ applied at time $t=0$. However, the theoretical values obtained for critical times are significantly lower than those determined experimentally. 


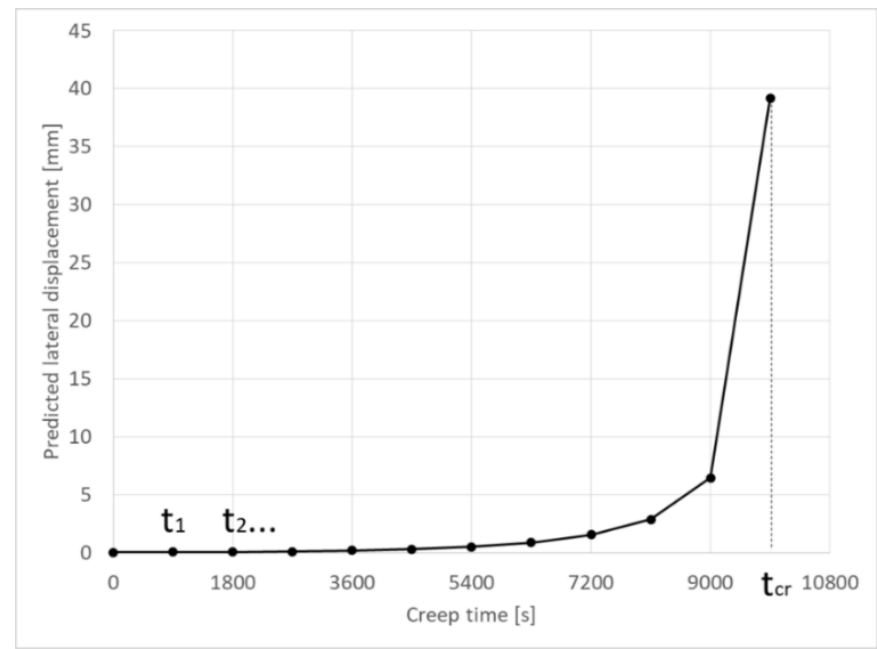

Fig. 7. Dependence between the predicted lateral displacement and creep time

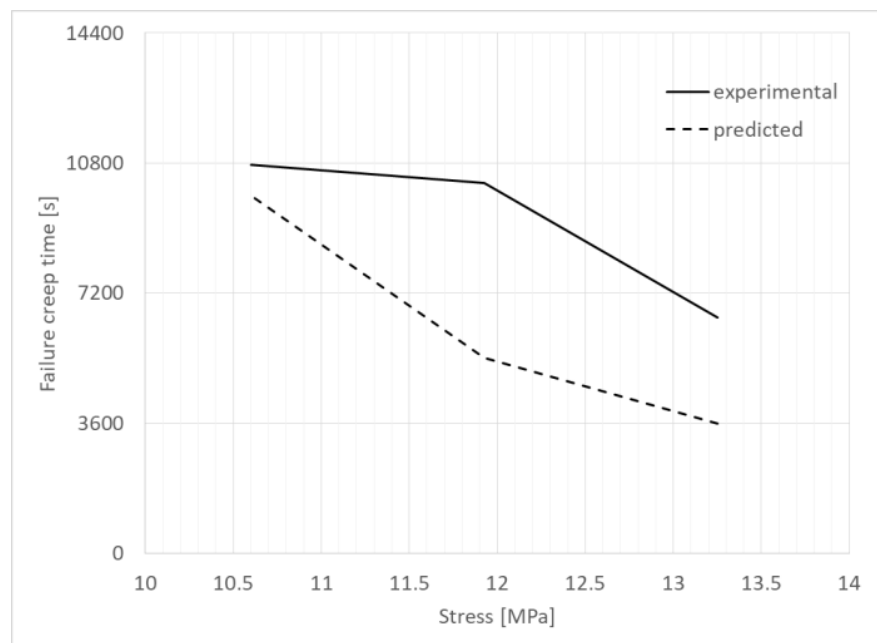

Fig. 8. Dependence between the predicted and experimental creep time and stress in the cross section of the element

\section{Conclusions}

The initial imperfections method allows us to predict the critical time, after which the loss of stability due to creep of the axially compressed steel member will occur. In order to use this method, it is necessary to know the values of the power creep law parameters. In the event if they are not known, their values should be determined experimentally. The nature of the critical time changes as a function of the

normal stress in a cross section is the same for the time calculated theoretically and the time determined in the laboratory. This time decreases as the compressive stress increases. However, there are significant differences between the theoretically predicted and experimentally determined times. This means that the initial imperfection method requires more careful analysis and modification.

\section{References}

[1] Беляев, Н. М. Сопротивление материалов. Москва: Hayka, 1965, 856 p.

[2] Blake, A. Handbook of mechanics, materials and structures. United States: John Wiley and Sons, 1985, 729 p.

[3] Hoff, N.J. (Editor) Creep in structures. Berlin: Springer-Verlag, 1962, 374p.

[4] Morovat, M.A., Engelhardt, M.D., Helwig, T.A., and Taleff, E.M. Experimental examination of creep buckling of steel columns in fire. In Structural Stability Research Council Annual Stability Conference 2016, SSRC 2016. Structural Stability Research Council 2016 (SSRC). pp. 248-261.

[5] Nabarro, F.R.N., de Villiers, H.L. Physics of creep and creep-resistant alloys. United Kigdom: Taylor and Francis Ltd 1995, 350p. [6] PN-ISO 6892-1:2016-09. Metallic materials - Tensile testing - Part 1: Method of test at room temperature.

[7] Вольмир, А.S. Устойчивость упругих систем. Москва: Наука, 1963, 879 p.

[8] Włóka, A., Pawłowski, K., Świerzko, R. Impact of high temperature creep on the buckling of axially compressed steel members. IOP Conference Series: Materials Science and Engineering, Volume 245, pp. 1-6. doi:10.1088/1757-899X/245/3/032052

[9] Włóka, A., Pawłowski, K., Świerzko, R. Investigation of high temperature creep of structural steel. 7th International Conference on Safety and Durability of Structures ICOSADOS: proceedings, UTAD, Portugal; 2016, p. 1-8 